\title{
Essay
}

\section{Conference Review: AnthropologyCon 2017}

\author{
Samuel Gerald Collins \\ Towson University \\ Matthew Durington \\ Towson University \\ Edward González-Tennant University of Central Florida Krista Harper \\ University of Massachussets Amherst \\ Marc Lorenc \\ University of Massachussets Amherst \\ Nick Mizer \\ Independent Scholar
}

AnthropologyCon 2017 transpired across multiple sites at the annual American Anthropology Association meeting in Washington, DC. The first event included a workshop on "Anthropology of/through Games" on Thursday afternoon, November 30, where participants learned about, brainstormed on, designed, and prototyped table-top games under the tutelage of Dr. Anatasia Salter, a game designer and games scholar from the University of Central Florida. In the second event, workshop participants and other interested attendees played games at the "\#AnthropologyCon Salon" on Saturday afternoon, December 2, including a couple of the table-top games prototyped during the first workshop. Finally, participants adjourned to the Board Room, a nearby gaming pub in the Dupont Circle neighborhood of Washington, DC, to play card games and role-playing games (Figure 1).

In lieu of a single-authored review of AnthropologyCon, the organizers have asked themselves key questions about their goals and future plans:

\section{Why AnthropologyCon Now? (Matthew Durington)}

The idea of AnthropologyCon started with a few conversations here and there between colleagues at past American

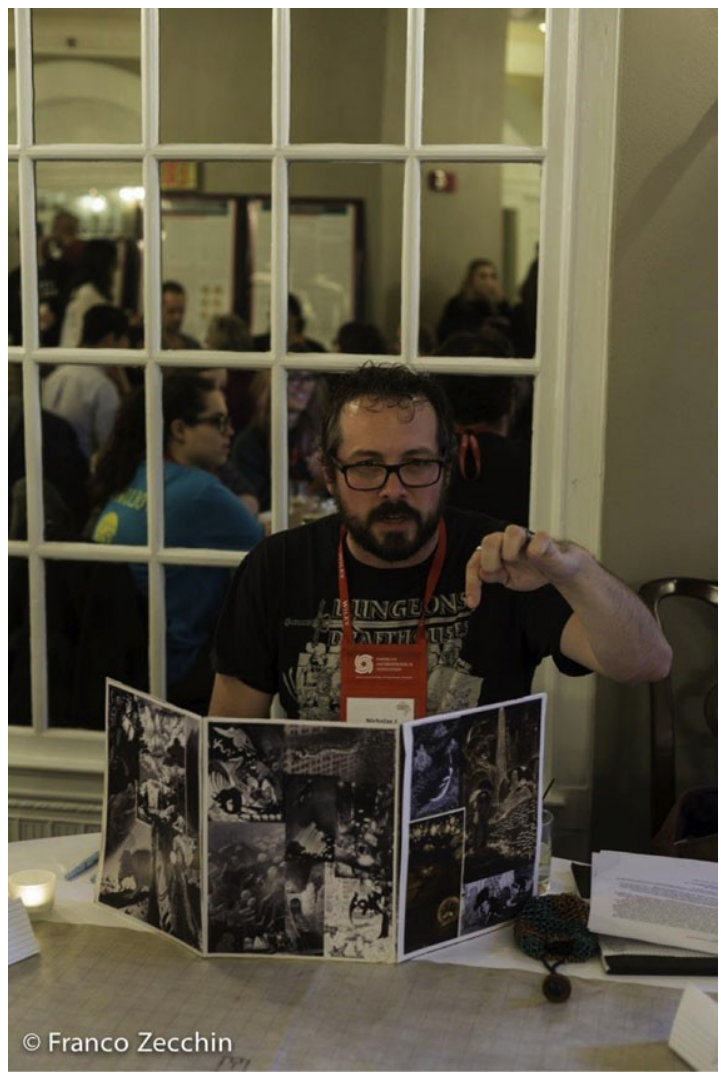

FIGURE 1. Nick Mizer guiding a game session at the AnthropologyCon salon at the 2017 American Anthropological Association annual meeting. (Photograph by Franco Zecchin) [This figure appears in color in the online issue] 
Anthropological Association annual meetings. "Did you see those guys in the concourse of the hotel playing Dungeons and Dragons on the floor around midnight last night?" These were the practitioners that embodied game culture in their anthropological practice and daily lives. We would overhear statements like, "I'm hacking the board game Risk to talk about warfare and capitalism in my course this semester . . . not sure it's working but the students love it." These were our anthropology colleagues who were hacking traditional games for teaching. "I'm using the MIT game-design kit for my methods course this year and thinking about game mechanics in my research," another would add. Some of our colleagues have been thinking about the theoretical and methodological capacities that could be gleaned from game design. For instance, "Anastasia Salter's blog ${ }^{1}$ had a great game link for Police Bear, ${ }^{2}$ and I'm using it to talk about police brutality and the Occupy Movement." Some conversations revolved around serious games and using these platforms to discuss social issues that are of interest to anthropologists. Finally, "I'm using gaming culture to discuss gender issues in American culture." These were the conversations looking to turn the anthropological lens to yet another cultural arena for all the classic reasons the field looks at various settings that are new or novel.

So why AnthropologyCon now? The interest in game design, game mechanics, and game-based learning is flourishing in many different academic fields and industries. Games serve as an interdisciplinary nexus for many of us. As an access point for learning, it is truly revolutionizing the way the classroom operates. Instructors are using games for teaching different topics while simultaneously employing game design to reshape pedagogy. It is an exciting time for games and anthropologists who play them, design them, or use them to teach. AnthropologyCon was an effort to move these disparate conversations into a unified and formal environment. In order to keep with the design focus of games, rather than simply organizing a panel of anthropologists talking about games, AnthropologyCon involved a workshop and development component in order to create games, critically approach game-based learning, and, at the end of the day, play! Our hope is that by bringing together a set of anthropologists to talk about all of these things in a cohesive and collective way will help us overcome some of the obstacles to incorporating (or popularizing) gaming within anthropology.

\section{What Have Been the Biggest Obstacles to Gaming in Anthropology? (Edward Gonzólez-Tenant)}

There are several obstacles to bringing gaming into anthropology. We understand games are straightforward, uncritical, rule-based activities that are intended for entertainment and fun. This commonsense perspective is usually based on our association with the games we played in childhood. In addition to the strict rules, we expect games to include winning and losing and to center on gameplay. We do not expect them to tackle important social issues or even explore alternative ways of seeing the world in a sensitive and ethnographically grounded manner. However, that is exactly what a whole cadre of games developers are doing. The web- site www.gamesforchange.org offers 173 games organized into topical categories that include economics, education, gender, health, human rights, and many more. Many inter- sect with ideas that are increasingly central to anthropology. For instance, the game Never Alone $e^{3}$ centers the voices of Alaska Native elders in a puzzle-based platformer ${ }^{4}$ game that interactively explores Iñupiat mythology.

So, perhaps the greatest obstacle to popularizing gaming within anthropology is not the games and their ability to engage us in important social issues but our discipline's inability to consider gaming as an intellectually relevant learning and pedagogical tool. Board, card, and video games are forms of visual media, and anthropologists have been examining and working with different forms of visual media for generations. Anthropology explores topics and experiences that are ideal for the creation of games. One of the core texts in game design-Jesse Schell's The Art of Game Design: A Book of Lenses—repeatedly states how useful anthropology is to game design.

In reality, there are no real obstacles to bringing games into anthropology. To reiterate, games are media, and to consume and produce media in anthropological ways you must make media. Anthropologists are starting to embrace graphic novels as a legitimate form of scholarship, as seen in the recent ethnographic series from the University of Toronto Press, and I think we will see a similar shift in attitude toward games in the near future. To understand how games are anthropologyand vice versa - start making games. AnthropologyCon offers a variety of approaches. If there is a game that you already like, begin by using it as a model with which to experiment, and change it bit by bit (a process also referred to as "hacking" a game). Until you embrace this creative (or inventive) process of making and playing anthropological games, you won't make and play any anthropological games yourself or with your students. So, I invite you to jump in feet first! Here's an encouraging hint: all games are anthropological games.

\section{Who's Interested in Making Games? Why? (Krista Harper)}

At AnthropologyCon 2017, we saw anthropologists with different interests and backgrounds come together, drawn in by a renewed interest in game-based scholarship within the discipline. Anthropologists in the mid-twentieth century were interested in games as a cultural phenomenon (see the work of Johannes Huizinga and Roger Caillois). With the advent of online gaming, scholarship on games and play is seeing a renaissance in cultural anthropology and archaeology (among others, see Boellstorff 2008; Malaby 2009; Nardi 2010; Reinhard 2017; Schüll 2012; Snodgrass 2016). Studying and communicating anthropology through game design is a more recent phenomenon, with a few notable exceptions (such as Mead and Bateson's Democracy and Dictators game). We are learning that games offer powerful ways to model systems and processes while also bringing participants' agency and decisions into focus. Anna Tsing and Elizabeth Pollman (2005) designed the Global Futures 
game, for example, as a tool for exploring the contingencies of globalization. Games operate through "procedural rhetoric" (Bogost 2007). Anthropologists, students, and research participants can un- pack this rhetoric and come to new understandings of tacit cultural rules, norms, and narratives through collaboratively analyzing and designing games. My course on "Anthropology of/through Games" pushes students to represent complex processes like refugee resettlement and disaster recovery by designing games based on anthropological texts. In science and technology studies, Joe Dumit has used game design as a research methodology while creating a game about hydraulic fracturing, commonly referred to as "fracking," to address this critical environmental issue of concern to many anthropologists. Jennifer Coffman (2013) collaborated with Jacob Mayiani Loorimirim to use his "culturally embedded board game" Eramat to study Maasai pastoralists' decision making about changing environmental conditions. Critical game design can be used in youth participatory-action research (YPAR), asin Dvera Saxton's work with youth from immigrant farmworker families to create games that would

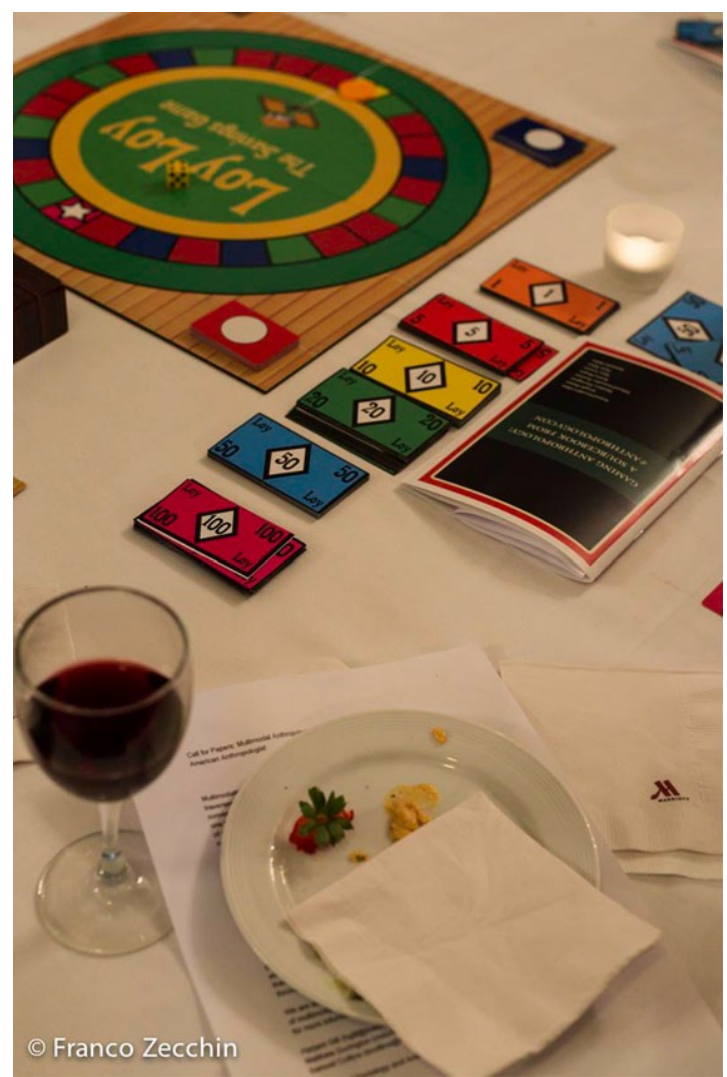

FIGURE 2. The game Loy Loy from UC Irvine's Institute for Money, Technology and Financial Inclusion being tested at the Anthropology- Con workshop at the 2017 American Anthropological Association annual meeting. (Photograph by Franco Zecchin) [This figure appears in color in the online issue]

inspire empathy and understanding of their parents' work in the strawberry fields in central California (Wenner-Gren 2016). These examples point to the potential of games as a multimodal genre for collaboratively investigating culture alongside research participants and for communicating anthropological ideas to our collaborators and a wider public.

\section{What's Next for AnthropologyCon? (Nick Mizer)}

I think this workshop did a great job of introducing anthropologists and anthropology students to the game-design process - how to take a concept or theme and build a game around it (Figure 2). Next year, I would like to retain that gamedesign element but also think about ways that we can help familiarize others with the great variety of games that already exist. At future AAA meetings, I am envisioning a dedicated "games-on-demand" space where attendees can drop in during the conference and that can be stocked with different games and staffed by people ready to recommend games and facilitate their induction into the world of gaming. Teaching a class that deals with race relations in the US? You might be interested in a little larp (live action role play) by Ross Cheung called Driving While Black. Want to encourage a conversation about the erasure and representation of Indigenous people to students and anthropologists? Let's look at First Nations of Catan as a tool to engage in that conversation. Besides the games on demand, I would also like to see us have some scheduled games throughout the conference and possibly also a space for featuring video games, which it was difficult to work within the game-design workshop.

It is important that we build on the body of knowledge about games that already exists, even as we promote the development of new games. While everyone who at- tends these workshops might not have the desire or the skillset to design a new game, facilitating games is an art form in its own right, and sharing both best practices and failures of implementation is 
important as we start incorporating games into anthropological research, teaching, and practice.

\section{What Games Would You Like to See Developed over the Next Two Years? (Marc Lorenc)}

In the next two years, I would like anthropologists to develop games that merge mechanics with "fieldwork moments" to introduce anthropological knowledge. Using platforms such as Twine, ${ }^{5}$ anthropologists can create choose-your-ownadventure stories that familiarize students with method and theory while also demonstrating the difficulty of navigating fieldwork dilemmas. These stories can deal with a variety of topics, such as ethics, community engagement, and research design, while introducing students to various regions, cultural practices, and beliefs. In this way, games allow anthropologists to bridge the sociality of the classroom with the immersive, experiential aspects of fieldwork, serving as a possible training tool in the process. In addition, anthropologists can translate their theory and methods to add new game mechanics to an already robust palette. ${ }^{6}$ Using mechanics such as action point allowance system, variable player powers, and worker placement in relation to ethnographic methods, we can create games that emphasize the ground-up approach valued within anthropology. By showcasing moments of discovery and storytelling that occur in the field, we can create immersive gaming experiences that facilitate empathy, reflection, and experiential learning. As anthropologists engaging a complex, diverse world, we should embrace the ability of games to bring people together, using the shared social space of gaming to develop an empathetic understanding of one another.

\section{What's the Relationship between Multimodality and Anthropology Games? (Samuel Gerald Collins)}

Multimodal anthropology describes a critical movement in multiple subfields of current anthropology (Collins, Durington, and Gill 2017). It begins with a reflexive accounting of the collaborative media that has enabled anthropological labor, and it continues through emergent participatory platforms that include film, photography, social media, drawing, and performance. Through (frequently) digital dissemination, each of these is shared, negotiated, (re)mixed, and, ultimately, changed. Recursively, each new inclusion in multimodality changes what we think of as multimodal anthropology, defining an arc of inquiry and intervention rather than an ontology. It was only a matter of time before games are caught up in this foment.

Like other media in multimodal anthropology, games have a long, mostly unacknowledged history in the field. That is, outside of the anthropology of play and (later) the burgeoning field of games studies in anthropology, there are multiple moments when anthropologists and their many interlocutors have come together in a game space to produce knowledge, affect, and collaborative meaning. Some of these moments have been critical and even a bit cheeky, as in Anna Tsing and Elizabeth Pollman's (2005) Global Futures. Other games have been altogether more serious - and here I think of the cognitive testing of Indigenous peoples, a "fun" activity with very real consequences (Fischer and Kronenfeld 2016).

But games, like other multimodal anthropologies, shift across the course of their practice. They may begin in an ap- parent consensus over the rules, the representational tools and techniques that enable gameplay, but that precarious agreement must by definition be reestablished over and over again, changing the game along lines of flight that none of the players could have anticipated and, in the process, introducing new understandings and communication. Every element of the game contributes to this emergence: the discourse of play, the haptic sensation of game pieces or keystrokes, the social alliances and competitions. Once we begin the anthropological game, the outcome is always unknown, and every game is different.

\section{NOTES}

Please see the website www.anthropologycon.org for materials related to AnthropologyCon 2017, including a collection of further essays on gaming and anthropology by the authors.

1. http://selfloud.net/.

2. http://www.auntiepixelante.com/policebear/.

3. http://neveralonegame.com/.

4. A platformer game is one where the player guides a character to jump from object to object to move through an environment. Well-known examples include Super Mario Brothers and The Legend of Zelda games.

5. http://twinery.org.

6. http://boardgamegeek.com/browse/boardgamemechanic.

\section{REFERENCES CITED}

Boellstorff, Tom. 2008. Coming of Age in Second Life: AnAnthropologist Explores the Virtually Human. Princeton, NJ: Princeton University Press. Bogost, Ian. 2007. Persuasive Games: The Expressive Power of Videogames.

Cambridge, MA: MIT Press.

Coffman, Jennifer 2013. “Art Around the World: Kenya and Virginia.” Anthropology News 54 (4): n.p.

Collins, Samuel, Matthew Durington, and Harjant Gill. 2017. "Multimodality: An Invitation.” American Anthropologist 119 (1): $142-46$.

Fischer, Edward, and David Kronenfeld. 2016. "Simulation (and Modeling)." In A Companion to Cognitive Anthropology, edited by David Kronenfeld, Giovanni Bennardo, and Victor C. de Murck, 210-26. New York: Blackwell. 
Malaby, Thomas M. 2009. Making Virtual Worlds: Linden Lab and Second Life. Ithaca, NY: Cornell University Press.

Nardi, Bonnie 2010. My Life as a Night Elf Priest: An Anthropological Account of World of Warcraft. Ann Arbor: University of Michigan Press.

Reinhard, Andrew 2017. "Video Games as Archaeological Sites." In The Interactive Past: Archaeology, Heritage, and Video Games, edited by Angus A.

A. Mol, Csilla E. Ariese-Vandemeulebroucke, Krijn H. J. Boom, and Aris Politopoulos, 99-106. Leiden, NL: Sidestone.

Schell, Jesse 2014. The Art of Game Design: A Book of Lenses. Boca Raton, FL: CRC Press.

Schüll, Natasha D. 2012. Addiction by Design: Machine Gambling in Las Vegas. Princeton, NJ: Princeton University Press.

Snodgrass, Jeffrey G. 2016. "Online Virtual Worlds as Anthropological Fieldsites: Ethnographic Methods Train- ing via Collaborative Research of Internet Gaming Cultures.” Annals of Anthropological Practice 40 (2): 134-47.

Tsing, Anna, and Elizabeth Pollman. 2005. "Global Futures: The Game.” In Histories of the Future, edited by Daniel Rosenberg and Sarah Harding, 107-22. Durham, NC: Duke University Press.

Wenner-Gren. 2016. "Engaged Anthropology Grant: Serious Play: Anthropology and Game Design for Farmworker Health and Justice." Wenner-Gren blog. http://blog.wennergren.org/2016/07/eag_saxton/. 